\title{
ANALYSIS OF SUPRACUTANEOUS LOCKING COMPRESSION PLATE IN COMPOUND DISTAL METAPHYSEAL FRACTURES OF TIBIA- A PROSPECTIVE STUDY
}

\author{
Nagakiran K. V1, Prasad Soraganvi2, Bharadwaj M. S. C 3 , Sudeep M. N4, Gadiyar H. B5
}

${ }_{1}^{1}$ Assistant Professor, Department of Orthopaedics, PESIMSR, Kuppam, Andhra Pradesh, India.

${ }^{2}$ Associate Professor, Department of Orthopaedics, PESIMSR, Kuppam, Andhra Pradesh, India.

${ }^{3}$ Resident, Department of Orthopaedics, PESIMSR, Kuppam, Andhra Pradesh, India.

${ }^{4}$ Assistant Professor, Department of Orthopaedics, PESIMSR, Kuppam, Andhra Pradesh, India.

5 Professor and HOD, Department of Orthopaedics, PESIMSR, Kuppam, Andhra Pradesh, India.

\section{ABSTRACT}

\section{BACKGROUND}

Complexity of open tibial fractures is on the rise with increased high-velocity road accidents. Temporary bony stabilization by external fixation avoids the instability at the fracture site and promotes healing of soft tissues. There is paucity of literature ascertaining the role of Locking Compression Plate (LCP) as external fixator device in compound tibial fractures. Hence a study was undertaken to assess the role of LCP as an external fixation tool in providing stability to the fractured bone.

\section{MATERIALS \& METHODS}

A prospective study was done on 21 consenting patients with open distal metaphyseal fractures of the tibia. Demographic, clinical and radiological assessment was done. Lower Extremity Functional Scale (LEFS) was used as an outcome measure.

\section{RESULTS}

There was a 90\% union rate in patients treated with LCP. There was an identifiable improvement in LEFS after treatment.

\section{CONCLUSION}

LCP as an external fixation device is an effective and safe method with good union rate.

\section{KEY WORDS}

Supracutaneous LCP, Locking Compression Plate, Open Tibial Fractures, External Fixation, LEFS, Supercutaneous LCP, Smoking, Non-Union of Bone.

HOW TO CITE THIS ARTICLE: Nagakiran KV, Soraganvi P, Bharadwaj MSC, et al. Analysis of supracutaneous locking compression plate in compound distal metaphyseal fractures of tibia- a prospective study. J. Evolution Med. Dent. Sci. 2019;8(05):316-320, DOI: 10.14260/jemds/2019/68

\section{BACKGROUND}

With an increase in high-velocity speeding motor vehicle accidents in the last decade, the complexity of tibial fractures has also seen a rise. Challenge lies in managing these tibial fractures because of their subcutaneous nature, poor vascularity and lack of circumferential muscular sleeve. Traditional open reduction and internal fixation with plates carry high rates of complications like infection, delayed union and non-union as a consequence of periosteal stripping. ${ }^{1,2}$

Management of an open fracture includes an early and aggressive debridement, intravenous antibiotics and temporary/definitive stabilization of fracture. ${ }^{3}$ Intramedullary inter-locking nailing as a definitive stabilization is indicated in Gustilo Anderson types I, II fractures. ${ }^{4}$ There is significant controversy with nailing as an option in Gustilo Anderson type III A and III B; especially when there is significant bone depth contamination. Also, voluminous distal meta-diaphyseal region and absence of metaphyseal cortical contact allows easy displacement at the fracture site.

'Financial or Other Competing Interest': None.

Submission 06-01-2019, Peer Review 25-01-2019,

Acceptance 28-01-2019, Published 04-02-2019.

Corresponding Author:

Dr. Prasad Soraganvi,

\#105, Hillview Block, PES Hospital Campus,

Kuppam-517425, Chittoor District,

Andhra Pradesh, India.

E-mail: drnagakiran@gmail.com

DOI: $10.14260 /$ jemds $/ 2019 / 68$

\section{(c) (i) $(5)$}

Temporary bony stabilization by external fixation avoids the instability at the fracture site and promotes healing of soft tissues.5,6 However external fixators for distal metadiaphyseal tibial fractures are bulky, inconvenient and it hampers gait.

Anatomically contoured Locking Compression Plate (LCP) as a "Supercutaneous Plate" addresses few of the drawbacks of external fixators ${ }^{7}$. LCP have superior holding power with fixed angular stability provided by screws locking onto the plate. There is paucity of literature ascertaining the role of LCP as external fixator device in compound Gustilo Anderson type III A and III B tibial fractures. Hence a study was undertaken to assess the role of LCP as an external fixation tool in providing stability to the fractured bone.

\section{MATERIALS AND METHODS}

This study was a prospective observational study done at PES Institute of medical sciences and research, Kuppam from March 2015 to Sept. 2018. The study subjects included all patients more than 18 years presenting with open distal meta-diaphyseal fractures of tibia (Inclusion criteria). Patients with open distal meta-diaphyseal fractures of tibia associated with vascular injuries were excluded from the study (Exclusion criteria).

A detailed history and physical examination were done as per the trauma protocol. After initial resuscitation routine blood and radiological investigations were done. Wound lavage was given in emergency room and injured limbs were temporarily splinted. Preoperative prophylactic antibiotic- 
Inj. Ceftriaxone $1 \mathrm{~g}$ and Tetanus toxoid injections were given. Patients were taken up for surgery on an emergency basis after deemed fit by anaesthetist and physician. Surgery was performed under spinal anaesthesia and tourniquet control. Surgical wound debridement was done. Fractured ends of bone were aligned and stabilized with appropriate precontoured LCP with bicortical screws as an external fixation device. Tension-free wound closure was done. Bulky sterile dressing and plaster splint was applied. Sutured wounds were regularly observed and dressed. Postoperative rehabilitation and gait training were begun from $2^{\text {nd-day }}$ post-surgery. After suture removal patients were discharged and followed up on an outpatient basis at regular intervals of 4 weeks and were assessed for soft tissue healing and bony union clinically and radiologically (Figure 1-4). Functional Outcome was assessed by the clinical and radiological union, and the Lower Extremity Functional Scale (LEFS).

The Lower Extremity Functional Scale (LEFS) is a patientreported outcome questionnaire containing 20 questions about a person's ability to perform everyday tasks. ${ }^{8}$ The LEFS is reliable and valid tool to assess group and individual changes. ${ }^{9}$

\section{RESULTS}

The present study included 21 patients satisfying inclusion criteria. All the 21 patients presented with distal metaphyseal fractures and underwent supracutaneous LCP fixation after thorough debridement. One patient was lost for follow-up after one-month post-surgery. All the remaining patients were followed-up till bony union. Results were analysed for 20 patients.

The average age at presentation was 54.5 yrs. (Range 2566 yrs.). There was a predominance of the male gender in the study group (M: F=3:1). Side distribution of the injured limbs was equal (Right: Left=1:1). The presentation of fractures with Gustilo Anderson Type II, IIIA and IIIB were 1, 8 and 11 respectively (Chart 1). The average follow-up was 7 months (Range 6-9 months).

Out of 20 patients, one patient has screw site infection, which settled with local dressings and oral antibiotics. There were no screw back out, deep infection, and loss of reduction (Table 1.).In two of the patients non-union was diagnosed and they underwent additional procedures to promote bony union (Figure 5-8).
The average LEFS among patients with union and nonunion was 73.27 and 29.5 respectively (Chart 2.). Among patients with non-union the scores improved to 70 after surgical intervention to promote bony union.

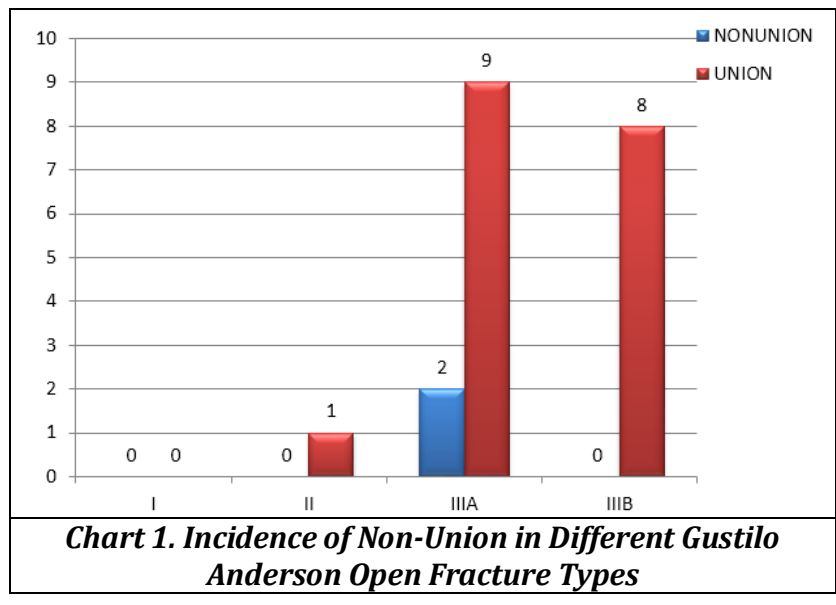

\begin{tabular}{|c|c|}
\hline Superficial /Screw Site Infection & 1 \\
\hline Deep Infection & 0 \\
\hline Loss of Reduction & 0 \\
\hline Non-Union & $2^{*}$ \\
\hline Joint Stiffness & $2^{*}$ \\
\hline
\end{tabular}

Table 1. Analysis of Complication in Our Study

*-Same two patients who had non-union and also had joint stiffness

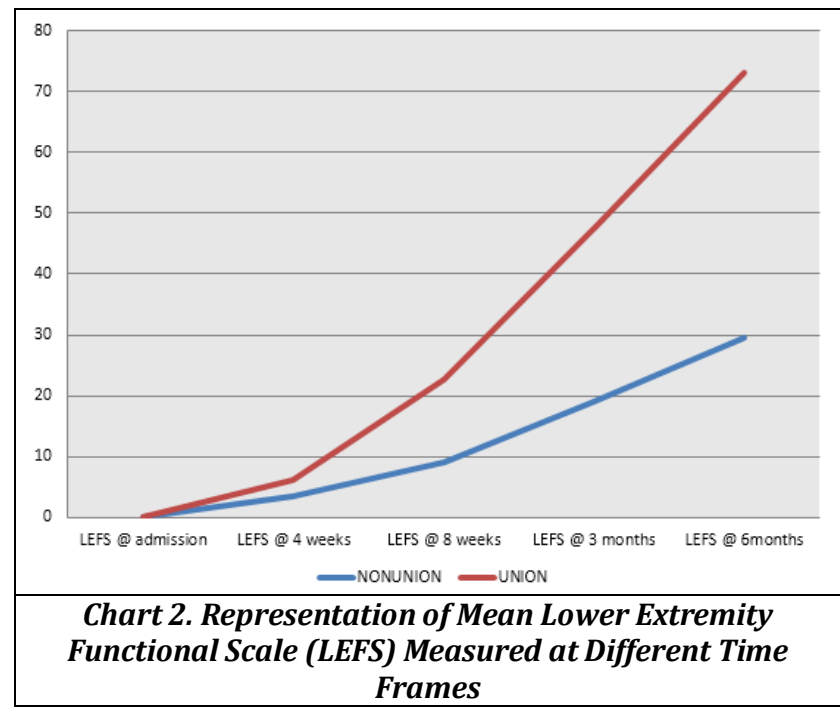



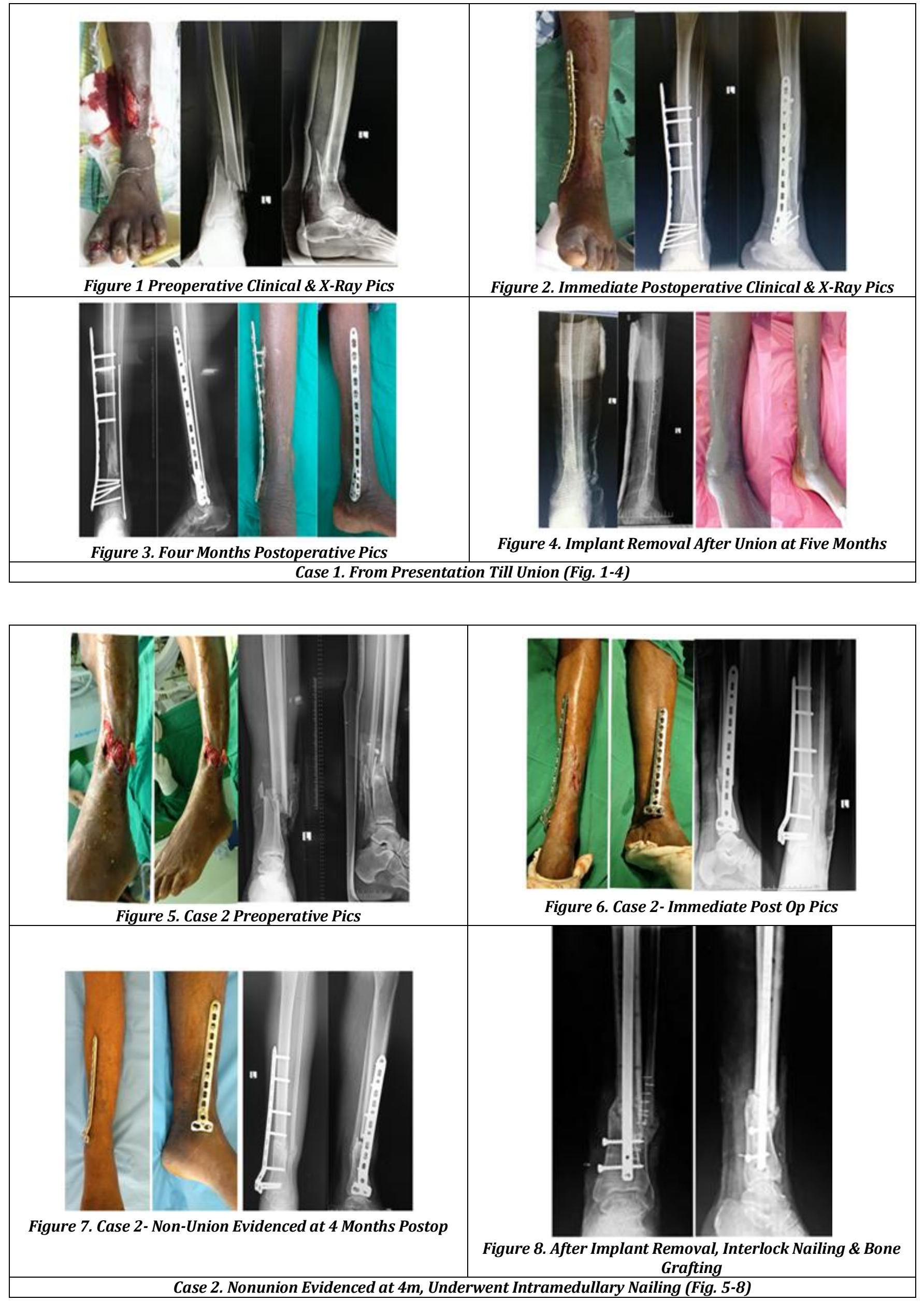


\section{DISCUSSION}

The prime objectives of treatment of open fractures of distal tibia are the prevention of infection, promotion of soft tissue healing, stabilization of fracture and restoration of function of affected extremity.9,10,11,12 A good surgical debridement is of paramount importance in eliminating the chances of infection. Primary internal fixation is preferred wherever possible in preventing malunion and early mobilization and return to activities. ${ }^{13,14}$ External fixators have a role in severe comminuted open fracture wherein they stabilize the bone at a distance from injured area thereby promoting healing of soft tissues and preventing additional damage to vascularity.5,6,15,16 The drawbacks of traditional external fixators are pin tract infection, loosening, loss of reduction, delayed and non-union.

LCP as an external fixator device has been described in the literature. Kloen $\mathrm{P}$ et al. in 2012 coined the term "Supercutaneous plating" and used LCP as an external fixator in diverse acute and chronic infectious non-union of distal tibia. ${ }^{7}$ They reported good union and infection control with the use of LCP.

In our study, there was a $90 \%$ union rate in distal tibial fractures treated with LCP as an external fixation device. All the patients in the united group had good to excellent results as per LEFS at the end of 6 months. Our study had predominantly Gustilo Anderson type III cases. The two patients who had non-union underwent secondary surgeries like interlocking nailing and bone grafting. Eventually, these fractures united in these patients and LEFS scores improved from 25 to 70 in patient- 2 and 34 to 70 in patient-9. Retrospectively these patients were interviewed again and both of them regularly continued to smoke beedies throughout their rehabilitation period even in spite of repeated warnings. In a meta-analysis done in 2016 investigators found that smokers have an increased incidence of delayed union and twice the risk of non-union as compared to non-smokers. ${ }^{17}$

LCP 18 has advantages over traditional fixators. They are less bulky and cumbersome and can be easily hidden in patients clothing. They offer multidirectional screw placement with superior pull out rates. The pitch of locking screw is less compared to Schanz pins of external fixators and provides sturdy purchase in metaphyseal cancellous bones and in osteoporotic patients. The locking screws engage on to the locking plate and chances of secondary loss of reduction as in traditional external fixators are negligible. Implant removal can be done under local anaesthesia

\section{Limitations}

This was a single centre study with a smaller sample size, hence projection of the results for a general population may not be accurate. A multicentre study with larger sample and longer-term follow-up is needed for confirming the results obtained in the present study.

\section{CONCLUSION}

In our study, we have found that an LCP as an external fixation device is an effective, safe and promising method with good union rates. In a certain subset of patients where internal fixation is a contraindication (absolute / relative), external fixation with LCP plays an important role.
Supracutaneous LCP alone can also be used as a definitive fixation method.

\section{REFERENCES}

[1] Im GI, Tae SK. Distal metaphyseal fractures of tibia: a prospective randomized trial of closed reduction and intramedullary nail versus open reduction and plate and screws fixation. The Journal of Trauma 2005;59(5):1219-23, discussion 1223.

[2] Janssen KW, Biert J, Van Kampen A. Treatment of distal tibial fractures: plate versus nail: a retrospective outcome analysis of matched pairs of patients. Int Orthop 2007;31(5):709-14.

[3] Kindsfater K, Jonassen EA. Osteomyelitis in grade II and III open tibia fractures with late debridement. J Orthop Trauma 1995;9(2):121-7.

[4] Tornetta P. Tibial fractures. In: Dee R, Hurst LC, Gruber MA, et al. eds. Principles of Orthopedic Practice. $2^{\text {nd }}$ edn. New York: McGraw-Hill 1997: p. 519-30.

[5] Collinge C, Kuper M, Larson K, et al. Minimally invasive plating of high-energy metaphyseal distal tibia fractures. J Orthop Trauma 2007;21(6):355-61.

[6] Collinge C, Kennedy J, Schmidt A. Temporary external fixation of the lower extremity: a survey of the orthopaedic trauma association membership. Orthopedics-Healio 2010;33(4).

[7] Kloen P. Supercutaneous plating: use of a locking compression plate as an external fixator. J Orthop Trauma 2009;23(1):72-5.

[8] Binkley JM, Stratford PW, Lott SA, et al. The Lower Extremity Functional Scale (LEFS): scale development, measurement properties and clinical application. North American Orthopaedic Rehabilitation Research Network. Phys Ther 1999;79(4):371-83.

[9] Okike K, Bhattacharyya T. Trends in the management of open fractures. A critical analysis. J Bone Joint Surg (Am) 2006;88(12):2739-48.

[10] Zalavras CG, Patzakis MJ. Open fractures: evaluation and management. J Am Acad Orthop Surg 2003;11(3):212-9.

[11] Pape HC, Webb LX. History of open wound and fracture treatment. J Orthop Trauma 2008;22(Suppl 10):S133-4.

[12] Chen AT, Vallier HA. Non-contiguous and open fractures of the lower extremity: epidemiology, complications, and unplanned procedures. Injury 2016;47(3):742-7.

[13] Gristina AG, Costerton JW. Bacterial adherence to biomaterials and tissue. The significance of its role in clinical sepsis. J Bone Joint Surg (Am) 1985;67(2):26473.

[14] Giotakis N, Narayan B. Stability with unilateral external fixation in the tibia. Strateg Trauma Limb Reconstr 2007;2(1):13-20.

[15] Clifford RP. Open fractures. In: Ruedi TP, Murphy WM, eds. AO principles of fracture management. Stuttgart/ New York: Thieme Verlag 2000: p. 617-37.

[16] Gustilo RB, Merkow RL, Templeman D. The management of open fractures. J Bone Joint Surg Am 1990;72(2):299-304. 
[17] Pearson RG, Clement RGE, Edwards KL, et al. Do smokers have greater risk of delayed and non-union after fracture, osteotomy and arthrodesis? A systematic review with meta-analysis. BMJ Open 2016;6(11):e010303.
[18] Smith WR, Ziran BH, Anglen JO, et al. Locking plates: tips and tricks. Instr Course Lect 2008;57:25-36. 